\title{
Invasive breast cancer following bilateral subcutaneous mastectomy in a BRCA2 mutation carrier: a case report and review of the literature
}

\author{
Lidia Kasprzak1, Benoit Mesurolle², Francine Tremblay², Maria Galvez ${ }^{1}$, \\ Fawaz Halwani ${ }^{4}$ and William D Foulkes*1,5
}

Address: ${ }^{1}$ Department of Medicine, McGill University Health Centre, Montreal, Canada, ${ }^{2}$ Department of Radiology, McGill University Health Centre, Montreal, Canada, ${ }^{3}$ Department of Surgery, McGill University, Montreal, Canada, ${ }^{4}$ Department of Pathology, McGill University, Montreal, Canada and ${ }^{5}$ Program in Cancer Genetics, Departments of Oncology and Human Genetics, McGill University, Montreal, Canada

Email: Lidia Kasprzak - lidia.kasprzak@mail.mcgill.ca; Benoit Mesurolle - benoit.mesurolle@muhc.mcgill.ca;

Francine Tremblay - francine.tremblay@muhc.mcgill.ca; Maria Galvez - maria.galvez@muhc.mcgill.ca;

Fawaz Halwani - fawaz.halwani@muhc.mcgill.ca; William D Foulkes* - william.foulkes@mcgill.ca

* Corresponding author

Published: 04 August 2005

World Journal of Surgical Oncology 2005, 3:52 doi:10.1186/1477-7819-3-

52

This article is available from: http://www.wjso.com/content/3/l/52

(c) 2005 Kasprzak et al; licensee BioMed Central Ltd.

This is an Open Access article distributed under the terms of the Creative Commons Attribution License (http://creativecommons.org/licenses/by/2.0), which permits unrestricted use, distribution, and reproduction in any medium, provided the original work is properly cited.
Received: 25 May 2005

Accepted: 04 August 2005

\begin{abstract}
Background: Primary prevention of breast cancer through prophylactic mastectomy can reduce the risk of malignancy in high-risk individuals. No type of mastectomy completely removes all breast tissue, but a subcutaneous mastectomy leaves more tissue in situ than does a simple mastectomy.
\end{abstract}

Case presentation: We report a case of invasive breast cancer in a BRCA2-positive woman 33 years after bilateral subcutaneous mastectomy. To our knowledge, only one case of primary breast cancer after prophylactic mastectomy in a BRCAI-positive patient has been reported in the literature and none in BRCA2-positive individuals.

Conclusion: Careful documentation and long follow-up is essential to fully assess the benefits and risks of preventive surgical procedures in BRCAI and BRCA2 mutation carriers.

\section{Background}

The risk of breast cancer in women who inherit a germline mutation in the BRCA1 gene can be as high as $20 \%$ by the age of 40 and $50 \%$ by the age of 50 [1] and as high as $13 \%$ by the age of 40 and $60 \%$ by the age of 50 in BRCA2 mutation carriers [2]. These estimates apply to individuals who belong to very high risk, multiple-case breast cancer families. Prophylactic surgery to reduce cancer risk remains an option for carriers of BRCA gene mutations; however, its efficacy is likely to depend on the ability to remove nearly all breast tissue. Different surgical procedures, (subcuta- neous or a simple mastectomy), limited patient follow-up and lack of adequate control population confound the numerous studies on this subject. Only three reports have specifically addressed the extent of risk reduction by prophylactic breast removal in BRCA1 and BRCA2-positive individuals [3-5]. Most surgeons believe that subcutaneous mastectomy (SCM) is not optimal for prophylaxis because a substantial amount of breast tissue remains in the nipple-areola complex and on the skin flaps, and therefore it has fallen into disuse. Here, we report a case of breast cancer occurring following a SCM. A literature 


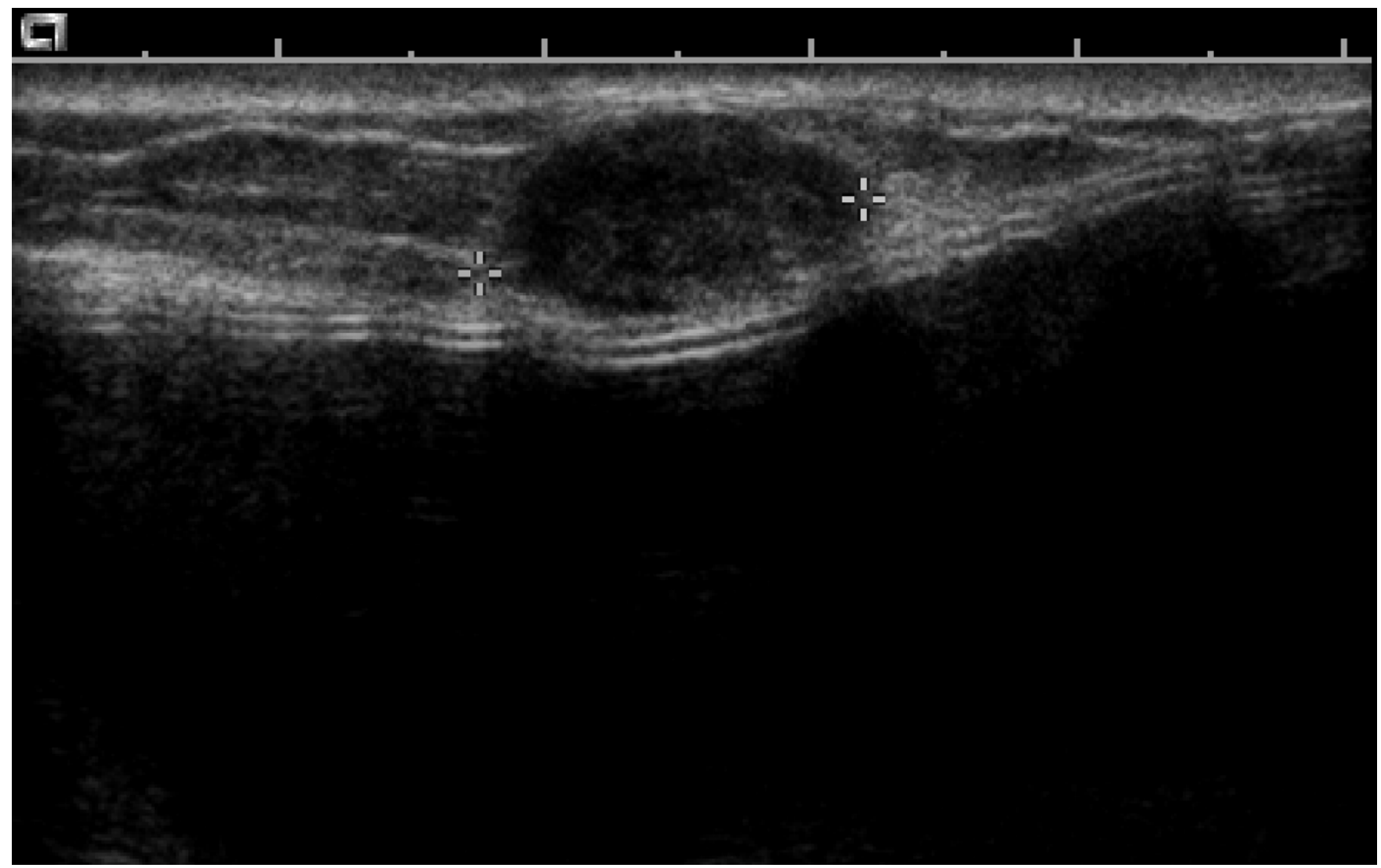

Figure I

Sonographic examination: $15 \mathrm{~mm}$ hypoechoic solid, non-calcified circumscribed mass, with a thin echoic rim, benign in appearance, located in subcutaneous fat at 9 o'clock in the left breast.

review using PubMed, searching from 1994 to the present, revealed this to be the first reported case of breast cancer occurring post-SCM in a carrier of a BRCA2 gene mutation. We discuss the possible implications of this seemingly uncommon finding.

\section{Case Presentation}

A 49 year old G3P2A1 presented in 2002 with a six month history of a painless lump in her inner left breast. She had undergone bilateral SCM with immediate implantation of silicone prostheses at the age of 16 due to extensive fibrocystic breast disease with adenosis. On physical examination a firm, mobile, $1.5 \mathrm{~cm}$ nodule was palpated superficially. There was no associated skin retraction or thickening. No enlarged abnormal nodes were palpable. We performed mammographic and sonographic examinations. Mammography, of limited value because of the previous SCM, did not show any obvious abnormality. Sonographic examination revealed a $1.5 \mathrm{~cm}$ in size, hypoechoic, solid, non-calcified, circumscribed mass, grossly ovoid with a thin echoic rim, located in the subcutaneous fat at 9 o'clock in the left breast (Figure 1). Minimal vascular pole was identified on conventional color sonography. The imaging findings appeared to indicate a benign nature of the lesion; however, based on the family history, patient age, and the recent occurrence of the nodule, excisional biopsy was performed. An infiltrating ductal carcinoma, apocrine type, grade 2 of 3 of modified Bloom and Richardson, with associated ductal carcinoma in situ, cribriform type, nuclear grade 2 of 3, occupying $10 \%$ of tumor mass (Figures 2A and 2B) was identified. Estrogen receptor status was strongly positive on most malignant cells, progesterone receptor moderately positive on $50 \%$ of malignant cells and HER-2/neu was negative (score 0) with no membrane staining of malignant cells. There was no evidence of malignancy in 23 lymph nodes examined following the left axillary contents dissection.

Subsequently, the proband was referred for genetic counseling and found to carry BRCA2: 6503delTT, a mutation previously described in the French Canadian population [6]. Family history (Figure 3) was significant for breast 


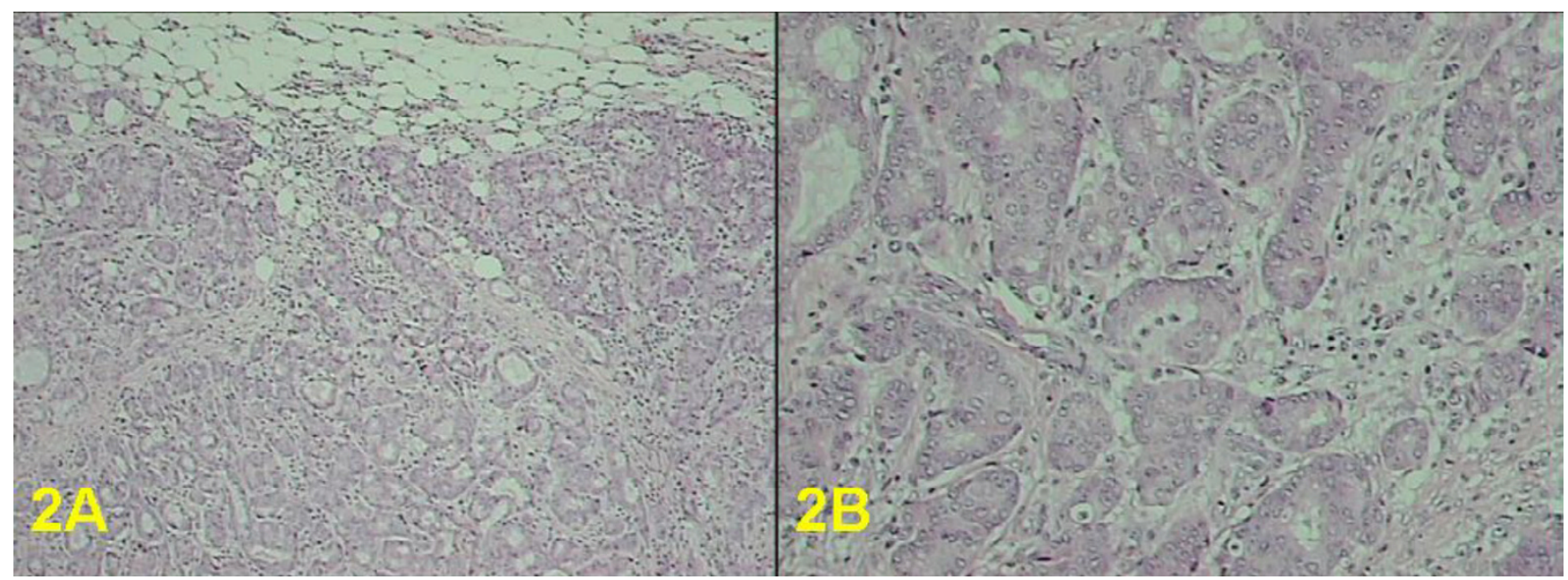

\section{Figure 2}

photomicrograph 2A) Invasive ductal carcinoma, apocrine type: tumor exhibits an irregular invasive border and forms glandular structures. Hematoxylin and eosin stain, original magnification $\times 40.2 B$ ) Invasive ductal carcinoma, apocrine type: cytological characteristics of intermediate nuclear grade, prominent nucleoli, and eosinophilic granular cytoplasm. Hematoxylin and eosin stain, original magnification $\times 100$.

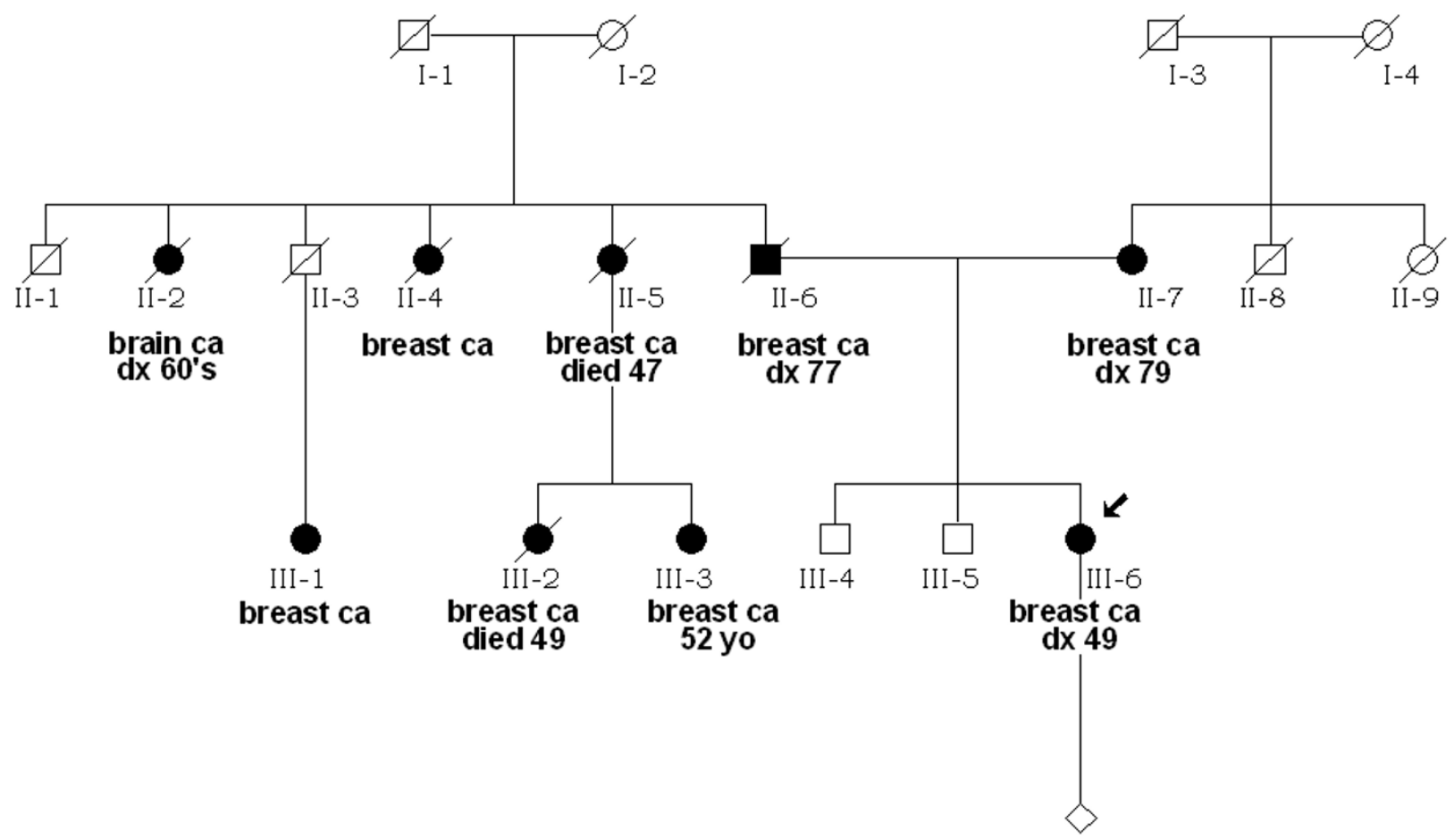

Figure 3

Pedigree of the family with germline BRCA2: 6503delTT mutation. All individuals affected with cancer (ca) are depicted by filledin symbols. Individual ID numbers, age at the time of diagnosis $(\mathrm{dx})$ and/or death are below each symbol. 
cancer in proband's father (II-6) who was diagnosed at the age of 77 and mother (II-7) diagnosed at 79. A 52 years old paternal cousin (III-3), also affected with breast cancer, was previously identified as a BRCA2 mutation carrier at another institution. Of note, individual III-3's mother (II-5) and sister (III-2) both had breast cancer and died at 47 and 49 years of age, respectively. There were only two paternal aunts known to have been affected with breast cancer at the time of patient's bilateral SCM.

Given the diagnosis of invasive breast cancer and BRCA2 mutation carrier status, our proband opted for prophylactic bilateral salpingo-oophorectomy with hysterectomy, as well as removal of the nipple-areola complex along with remaining breast tissue. The pathology examination identified the presence of bilateral adnexal stromal hyperplasia, several leiomyomata in the myometrium as well as simple ductal epithelial hyperplasia without atypia in the mastectomy specimen. There was no evidence of malignancy.

\section{Discussion}

Currently available management strategies for women who carry inherited predisposition to develop breast cancer are limited given the lack of prevention methods with proven efficacy. Furthermore, there have been no prospective, controlled trials of the breast cancer risk reduction associated with bilateral prophylactic mastectomy. Such studies are unlikely to take place due to ethical and practical considerations. Prophylactic mastectomy, whether subcutaneous or total, significantly reduces, but does not eliminate, the risk of breast cancer in high-risk individuals.

Several studies showed that breast reduction procedures substantially lower the risk of breast cancer. Recently, Brinton et al [7] confirmed that the magnitude of cancer risk reduction is directly related to the amount of tissue removed during the operation. With a SCM, the nippleareola complex is preserved and some of the underlying breast tissue remains on the skin flaps. When SCM is intended as prophylaxis against breast cancer, the surgeon's aim is to remove as much tissue as possible. It is plausible that a less thorough removal of glandular tissue may have taken place given the indication for surgery in our patient's case. It is generally agreed that the prophylactic nature of bilateral mastectomy in an unaffected BRCA1 or BRCA2 mutation carrier calls for the most complete breast tissue removal. This viewpoint makes SCM a less desirable choice. Skin-sparing mastectomy [8] could be seen as a partial compromise and appears to be an increasingly popular option for women at high risk. More recently, geneticists have questioned the rejection of simple SCM as a viable procedure in such women. It is argued that the magnitude of the risk reduction offered by SCM, when combined with its greater cosmetic acceptability, is sufficient to keep this option available to women [9].

There are numerous reports in the literature describing the occurrence of breast cancer after SCM [10,11]. Subsequently, the perception exists that SCM fails to eliminate the risk of breast cancer. Although the extent of risk reduction achieved by SCM is limited given that about 5$10 \%$ of the mammary tissue remains in situ, it is thought to be of the order of $>85 \%[4,12]$. As stated above [9], at this level of risk reduction, SCM would have a greater effect on breast cancer rates in $B R C A 1 / 2$ carriers than would total mastectomy if at least $50 \%$ of $B R C A 1 / 2$ carriers chose preventive SCM. Currently, preventive bilateral total mastectomy rates are about $20 \%$ in most populations.

The first retrospective study of efficacy of prophylactic mastectomy carried out by Hartmann et al [12] included 18 subjects later confirmed to be carriers of deleterious mutations in the BRCA genes but, unfortunately, it had insufficient statistical power to detect a difference in the risk reduction between total and SCM. In this cohort, all breast cancers $(n=7)$ were diagnosed in women who had undergone SCM (total of 950). None were known to be BRCA1/2 mutation carriers. Of the seven cases, only one occurred in the nipple-areolar area. Not surprisingly, the majority of the high-risk women $(n=17)$ described in the subsequent report [3] underwent SCM. After a median of 13.4 years of follow-up, none of the BRCA1/2 germ-line mutation carriers has developed breast cancer. The authors concluded that at least $90 \%$ risk reduction could be expected among women with confirmed BRCA mutation status following prophylactic bilateral SCM. MeijersHeijboer et al [4] report the initial results of a prospective study of 76 women with deleterious BRCA1 or BRCA2 mutations who chose to undergo bilateral simple mastectomy and no breast cancers were observed after a mean follow-up of $2.9 \pm 1.4$ years. The Prevention and Observation of Surgical End Points (PROSE) Study Group findings [5] support the notion that bilateral mastectomy results in approximately $90 \%$ breast cancer risk reduction. Of 105 BRCA mutation carriers, only two women (1.9\%) developed breast cancer 2.3 and 9.2 years after SCM. The first breast cancer case was diagnosed at the age of 28 years in the BRCA2 mutation carrier who presented with a palpable axillary mass at 27 months post-SCM. Subsequently, metastatic adenocarcinoma in an axillary lymph node was identified and it was most likely consistent with a primary breast cancer already present at the time of SCM. It is important that this case is not considered as a failure of SCM, and it should be therefore classified as a recurrence which would have likely taken place despite the surgery. The second breast cancer case occurred in a BRCA1 carrier at the age of 41 years. 
Table I: Studies assessing efficacy of bilateral prophylactic mastectomy (PM) in BRCAI and BRCA2 carriers

\begin{tabular}{llll}
\hline & Hartmann et al [3] & Meijers-Heijboer et al [4] & Rebbeck et al [5] \\
\hline Study recruitment centers & USA & Netherlands & USA, Canada, UK, Netherlands \\
Median follow-up (yrs) & 13.4 & 2.8 & 5.5 \\
Mean age at surgery (yrs) & 39 & 36 & 38 \\
Number of PM patients & 18 & 76 & 105 \\
Number of controls & - & 63 & 378 \\
Type of study & Retrospective cohort & Prospective cohort & Case-control \\
Primary invasive breast cancer & & 0 & I (BRCAI carrier) \\
- in cases (after PM) & 0 & $8(13 \%)$ & I84 (49\%) \\
- in controls & - & &
\end{tabular}

When hereditary predisposition to breast cancer is being assessed, it is important to consider the impact of the agerelated penetrance of the BRCA1 and BRCA2 genes. $B R C A 1$ has a higher penetrance than $B R C A 2$ in the premenopausal years [1]. The benefits of preventive surgery will be proportionally greater for an older $B R C A 2$ carrier than an older BRCA1 carrier, and therefore if a BRCA2 carrier discovers her mutation status when she is peri- or post-menopausal, the potential benefits of preventive mastectomy should not be understated, as the breast cancer risks do not significantly diminish following menopause.

In our review of the literature (see Table 1), only one primary breast cancer has been reported to occur in a cohort of 207 BRCA1/2 mutation carriers who opted for preventive surgery. It could be argued that the efficacy of the bilateral total mastectomy has not been studied adequately in the high-risk individuals to prove its absolute superiority over SCM. The total number of the BRCA1 and $B R C A 2$ carriers who have undergone this type of mastectomy is relatively small and the mean follow-up is rather short. Furthermore, the presence of a microscopic primary lesion at the time of surgery may result in subsequent recurrence that would be impossible to differentiate from a new primary breast cancer. Based on the above data, the risk-reducing effect of SCM should not be ignored when presenting prophylactic mastectomy options to women at high risk who find total mastectomy unacceptable and would not otherwise have considered surgical prevention. Nevertheless, the lack of popularity of this procedure among surgeons will likely limit its use.

The existing literature on the mammographic and sonographic appearance of breast cancer in BRCA-positive patients' reconstructed breasts is rather scanty. Pathologic studies have demonstrated that tumors in BRCA1 and BRCA2 mutation carriers are associated with morphologic features of continuous pushing margins [13], with a reduced potential for stromal infiltration explaining that this appearence might mimic benign-looking lesions at mammography [14] and breast sonography as well. Indeed, sonographic criteria of the mass in our case ovoid axis, thin pseudocapsule, posterior enhancement, and well defined margins - were in keeping with a benign nodule [15]. In addition, according to Giovagnorio criteria [16], the lesion described in our case, with a single vascular pole (type 2), was compatible with a benign lesion. Cconsistent with the Lamb et al study [17], this lesion appeared benign but was in fact a moderate to high-grade invasive cancer.

\section{Conclusion}

We report an unusual case of late occurrence of breast cancer after SCM in a BRCA2 mutation carrier. As these cases are so rare, the long-term risk of breast cancer following preventive mastectomy in BRCA1/2-positive individuals is likely to be very low. Nevertheless, vigilant, long-term surveillance based on clinical examination combined with breast sonography when indicated remains necessary, as delayed malignancy can occur.

\section{Competing interests}

The author(s) declare that they have no competing interests.

\section{Authors' contributions}

LK obtained family history, searched literature and drafted the manuscript, BM performed the sonographic assessment and assisted in manuscript preparation,FT initiated the report, provided patient history and referral for genetic counseling, managed the patient, MG carried out the molecular genetic studies, FH carried out the histopathological studies and provided diagnostic consultation, WDF obtained patient consent, assisted in literature search, helped to draft the manuscript and edited the final version. All authors read and approved the final manuscript. 


\section{Acknowledgements}

Written consent was obtained from the patient for publication of the case report. The authors thank Dr. D. Gareth Evans for helpful comments.

\section{References}

I. Easton DF, Ford D, Bishop DT: Breast and ovarian cancer incidence in BRCAI-mutation carriers. Breast Cancer Linkage Consortium. Am J Hum Genet 1995, 56:265-27I.

2. Easton DF, Steele L, Fields P, Ormiston W, Averill D, Daly PA, McManus R, Neuhausen SL, Ford D, Wooster R, Cannon-Albright LA, Stratton MR, Goldgar DE: Cancer risks in two large breast cancer families linked to BRCA2 on chromosome I3q I 2-I3. Am J Hum Genet 1997, 6 I: I20- I 28.

3. Hartmann LC, Sellers TA, Schaid DJ, Frank TS, Soderberg CL, Sitta DL, Frost MH, Grant CS, Donohue JH, Woods JE, McDonnell SK, Vockley CW, Deffenbaugh A, Couch FJ, Jenkins RB: Efficacy of bilateral prophylactic mastectomy in BRCAI and BRCA2 gene mutation carriers. I Natl Cancer Inst 200I, 93: I633-1637.

4. Meijers-Heijboer H, van Geel B, van Putten WL, Henzen-Logmans SC, Seynaeve C, Menke-Pluymers MB, Bartels CC, Verhoog LC, van den Ouweland AM, Niermeijer MF, Brekelmans CT, Klijn JG: Breast cancer after prophylactic bilateral mastectomy in women with a BRCAl or BRCA2 mutation. N Engl J Med 200I, 345:159-164.

5. Rebbeck TR, Friebel T, Lynch HT, Neuhausen SL, van 't Veer L, Garber JE, Evans GR, Narod SA, Isaacs C, Matloff E, Daly MB, Olopade $\mathrm{OI}$, Weber BL: Bilateral prophylactic mastectomy reduces breast cancer risk in BRCAI and BRCA2 mutation carriers: the PROSE Study Group. J Clin Oncol 2004, 22: I055-1062.

6. Tonin PN, Mes-Masson AM, Futreal PA, Morgan K, Mahon M, Foulkes WD, Cole DE, Provencher D, Ghadirian P, Narod SA: Founder BRCAI and BRCA2 mutations in French Canadian breast and ovarian cancer families. Am J Hum Genet 1998, 63:|34|-|35|.

7. Brinton LA, Persson I, Boice JD Jr, McLaughlin JK, Fraumeni JF Jr: Breast cancer risk in relation to amount of tissue removed during breast reduction operations in Sweden. Cancer 200I, 91:478-483.

8. Simmons RM, Adamovich TL: Skin-sparing mastectomy. Surg Clin North Am 2003, 83:885-899.

9. Metcalfe KA, Semple JL, Narod SA: Time to reconsider subcutaneous mastectomy for breast-cancer prevention? Lancet Oncol 2005, 6:43I-4.

10. Pennisi VR, Capozzi A: Subcutaneous mastectomy data: a final statistical analysis of $\mathbf{1 5 0 0}$ patients. Aesthetic Plast Surg 1989, I3:|5-2|.

II. Slade CL: Subcutaneous mastectomy: acute complications and long-term follow-up. Plast Reconstr Surg 1984, 73:84-90.

12. Hartmann LC, Schaid DJ, Woods JE, Crotty TP, Myers JL, Arnold PG, Petty PM, Sellers TA, Johnson JL, McDonnell SK, Frost MH, Jenkins RB: Efficacy of bilateral prophylactic mastectomy in women with a family history of breast cancer. N Engl J Med 1999, 340:77-84.

13. Lakhani SR, Jacquemier J, Sloane JP, Gusterson BA, Anderson TJ, van de Vijver MJ, Farid LM, Venter D, Antoniou A, Storfer-Isser A, Smyth E, Steel CM, Haites N, Scott RJ, Goldgar D, Neuhausen S, Daly PA, Ormiston W, McManus R, Scherneck S, Ponder BA, Ford D, Peto J, Stoppa-Lyonnet D, Bignon YJ, Struewing JP, Spurr NK, Bishop DT, Klijn JG, Devilee P, Cornelisse C], Lasset C, Lenoir G, Barkardottir RB, Egilsson V, Hamann U, Chang-Claude J, Sobol H, Weber B, Stratton MR, Easton DF: Multifactorial analysis of differences between sporadic breast cancers and cancers involving BRCAI and BRCA2 mutations. I Natl Cancer Inst 1998, 90: I|38-1|45.

14. Kaas R, Kroger R, Hendriks JH, Besnard AP, Koops W, Pameijer FA, Prevoo W, Loo CE, Muller SH: The significance of circumscribed malignant mammographic masses in the surveillance of BRCA I/2 gene mutation carriers. Eur Radiol 2004, I 4: I647-53.

15. Stavros AT, Thickman D, Rapp CL, Dennis MA, Parker SH, Sisney GA: Solid breast nodules: use of sonography to distinguish between benign and malignant lesions. Radiology 1995, 196:123-134.

16. Giovagnorio F, Andreoli C, De Cicco ML: Color Doppler sonography of focal lesions of the skin and subcutaneous tissue. J Ultrasound Med 1999, 1 8:89-93.
17. Lamb PM, Perry NM, Vinnicombe SJ, Wells CA: Correlation between ultrasound characteristics, mammographic findings and histological grade in patients with invasive ductal carcinoma of the breast. Clin Radiol 2000, 55:40-44.
Publish with Biomed Central and every scientist can read your work free of charge

"BioMed Central will be the most significant development for disseminating the results of biomedical research in our lifetime. "

Sir Paul Nurse, Cancer Research UK

Your research papers will be:

- available free of charge to the entire biomedical community

- peer reviewed and published immediately upon acceptance

- cited in PubMed and archived on PubMed Central

- yours - you keep the copyright

Submit your manuscript here:

http://www.biomedcentral.com/info/publishing_adv.asp
BioMedcentral 